\title{
Review of endocrine syndromes associated with tumours of non-endocrine origin
}

\author{
C. B. HOBBS AND A. L. MILLER \\ From the Courtauld Institute of Biochemistry, The Middlesex Hospital Medical School, \\ London
}

SYNOPSIS During the past 10 years there has been particular interest in the occurrence of a number of endocrine syndromes in association with tumours of organs other than the endocrines. Evidence is increasing to suggest that these result from the formation of hormone-like substances by the tumours. The clinical importance and theoretical implications of these syndromes constitute the justification for reviewing them here.

One of the most interesting features of malignant disease is its liability to be associated with a variety of syndromes which are not as yet readily explicable in terms of tumour pathology or biochemistry. These have been well reviewed by Greenberg, Divertie, and Woolner (1964) and with special reference to carcinoma of the bronchus by Ross (1965).

In this review the various endocrine disturbances associated with neoplasms of non-endocrine tissues are discussed in turn.

\section{HYPOGLYCAEMIA}

There have been at least 100 patients reported with hypoglycaemia attributed to neoplasms not originating in the pancreas. The primary tumour in these patients is most commonly a connective tissue tumour of low-grade malignancy or a primary carcinoma of the liver.

The first probable case was recorded by Doege (1930) in a patient with a mediastinal fibrosarcoma. No blood sugar determinations were made but the patient was described as having episodes of irrational and maniacal behaviour before the removal of a tumour weighing $4 \frac{1}{2} \mathrm{lb}$. His behaviour became normal after the operation from which he made an uneventful recovery.

Since then there have been at least 60 further cases of hypoglycaemia occurring in association with connective tissue tumours of varying histology and degree of differentiation. All the tumours have been massive, averaging about $2.5 \mathrm{~kg}$. in weight, and all have been located in the thorax or abdomen, the Received for publication 2 December 1965. abdominal tumours being either intraperitoneal or retroperitoneal. Although in some cases hypoglycaemia has been provoked only by fasting, typical spontaneous hypoglycaemic attacks have been common, sometimes occurring before the presence of a tumour was suspected. In a number of cases, hypoglycaemic attacks have ceased after removal of the tumour, and returned with massive local recurrence or metastasis.

It was originally suggested that the hypoglycaemia was the result of 'glucose hunger' of the tumour but this view has not been substantiated. There has been little difference in glucose content of the arterial blood supplying, and the venous blood leaving, the tumours where this has been measured (August and Hiatt, 1958; Butterfield, Kinder, and Mahler, 1960), and excessive utilization of glucose by the tumours has not been demonstrated in vitro (Miller, Bolinger, Janigan, Crockett, and Friesen, 1959). Samaan, Lal, Fraser, and Welbourn (1965) suggest that the tumours produce hypoglycaemia by stimulating the secretion of pancreatic insulin, and Stern (1960) has suggested that release of leucine from the tumour into the blood of a leucine-sensitive person is the mechanism by which this response is mediated. However, Miller et al. (1959) cite a case in which pancreatectomy failed to maintain normoglycaemia, and Oleesky, Bailey, Samols, and Bilkus (1962) report leucine sensitivity in their patient with reversion to normality following radiotherapy to the tumour. Also leucine sensitivity is not invariably found in these patients (Butterfield et al., 1960).

Attempts to demonstrate the secretion of an insulin-like substance by the tumours, by assay of tumour extracts, have given variable results which 
are discussed by Odell (Lipsett, Odell, Rosenberg, and Waldmann, 1964). Such activity has been demonstrated in 11 out of 26 tumour extracts, using either the fat pad or rat diaphragm bio-assay techniques. The amounts present have varied between the very high level of 500 milliunits/g. to only 1.8 milliunits $/ g$. Specific immuno-assay procedures for insulin have often failed to demonstrate its presence even in tumour extracts with proven insulin-like activity on bio-assay. Efforts to demonstrate activity in the plasma of these patients have been even less rewarding. In only one case (Whitney and Massey, 1961) has increased activity been demonstrated by bio-assay, and in two cases by immuno-assay (Oleesky et al., 1962; Samaan et al., 1965). Failure may be attributable, at least in part, to unsatisfactory extraction procedures. Work on the BW 5147 experimental tumours of mice, which produces profound hypoglycaemia and may therefore be relevant to the present discussion, suggests that the hypoglycaemic factor elaborated may be rendered inactive by freezing or by extraction techniques usually used for insulin.

The situation is still far from clear, but there is evidence that in some cases the hypoglycaemic factor produced by the tumour may be immunologically distinct from insulin.

The first case of hypoglycaemia in association with a primary hepatic tumour was described by Nadler and Wolfer in 1929. In all cases the liver has been massively enlarged, being two or three times its normal weight. The tumour cells have contained large amounts of glycogen, the remaining normal liver cells being glycogen-depleted. The administration of adrenalin has failed to produce the normal rise in blood glucose which is due to mobilization of liver glycogen. It has been suggested therefore that hypoglycaemia is the result of excessive glycogen storage by the tumour cells, together with failure of the neoplastic cells to respond to the normal physiological mechanisms stimulating hepatic glycogenolysis. However, Schonfeld, Babbott, and Gundersen (1961) demonstrated a high insulin-like activity in an extract of such a tumour so that the mechanism of hypoglycaemia in the patients may eventually prove to be similar to that in the last group. It is interesting to note that Lowbeer (1961) was unable to find a single case of hypoglycaemia due to multiple hepatic metastases.

Far less commonly, hypoglycaemia has been associated with other tumours-adrenal carcinoma, carcinoma of the stomach, caecum or bile ducts, pseudomyxoma, and paraganglionoma. There is evidence that these tumours too may release a hypoglycaemic factor. In one case of adrenal carcinoma, a tumour extract produced a fall in the blood sugar of an animal. Tranquada, Bender, and Beigelma믈 (1962) reported the first case of hypoglycaemia occurring with an adenocarcinoma of the caecuns Tumour extracts from this patient were shown to have insulin-like activity using both the rae diaphragm and fat-pad methods. Immuno-assay bo two distinct methods, however, failed to detec insulin in the extracts, and serum insulin levels weres normal.

Recently, Unger, Lochner, and Eisentraut (1964) reported the detection of insulin by a highly specifie radioimmunochemical assay in a hepatic metastasis obtained from a patient with an undifferentiate bronchogenic carcinoma. The tumour contained 300 milliunits $/ g$. of insulin, roughly a thousand times that present in adjacent normal liver tissue. This tumour was also shown by immuno-assay to contaim a remarkably high concentration of glucagos $(0.5 \mu \mathrm{g}$./g.). Further experiments were undertaken to establish the similarity between glucagon and the glucagon-like substance detected by the assay, and it was shown that, like pancreatic glucagon, the substance was extremely sensitive to tryptic digestiom but was unaffected by incubation with cysteine, an that it had a similar electrophoretic mobility op cellulose acetate. The patient had no overt evidence of endocrinopathy and died before a full 'work ups was possible but one blood sugar determination was reported as $165 \mathrm{mg} . \%$. The authors estimate that assuming the hepatic metastasis analysed was. typical, the liver in this patient contained abou角 $500 \mu \mathrm{g}$. of glucagon. Less than $5 \mu \mathrm{g}$. is capable of producing hyperglycaemia in man.

\section{ADRENO-CORTICAL HYPERPLASIA}

Over a hundred cases of the association of adrene? cortical hyperplasia (Cushing's syndrome) with neoplastic disease of non-adrenal origin have been described since Brown (1928) first reported it. The tumour is usually a bronchial carcinoma or a thymoma. In a series reviewed by Riggs and Sprague (1961) these two sites accounted for 40 out of $5 \overline{8}$ cases. Histologically the bronchial tumours are of the oat cell type and the thymic tumours have a rathes unusual appearance consisting predominantly of epithelial rather than lymphoid tissue, so that Castleman, looking at a section of a thymic tumous was able to predict without fore-knowledge that the patient had adreno-cortical hyperplasia (Soutter? Sommers, Relman, and Emerson, 1957). Other siteso of the primary tumour include the pancreas, centra nervous system, breast, thyroid, prostate, and oeso? phagus. The adrenal glands in these patients are hyperplastic but non-tumourous. The patients show increased excretion of 17-oxogenic steroids in the 
urine and often markedly increased cortisol secretion rates (Prunty, Brooks, Dupré, Gimlette, Hutchinson, McSwiney, and Mills, 1963). Electrolyte disturbance, particularly hypokalaemic alkalosis, is relatively common. In spite of the fact that, as Prunty et al. (1963) point out, adreno-cortical hyperplasia in association with neoplastic disease is more rapidly advancing than the 'normal' type, the physical stigmata in these patients are often not marked. This has been attributed to the rather short life span of the patients due to the underlying malignancy, the fact that the majority of the patients are males in whom the stigmata are in any case less obvious, and to the weight loss and anaemia which are commonly present. It seems likely that a number of cases of this association lacking the florid clinical picture of adreno-cortical hyperplasia are being missed.

The initial theories proposed to explain this association are well reviewed by Riggs and Sprague (1961). It was suggested that the association was coincidental, but this could be discounted in view of the common association between thymoma and adreno-cortical hyperplasia. Another explanation was that massive hepatic involvement by metastases might impair conjugation and excretion of steroids, but this is unlikely since massive hepatic involvement is uncommon in these patients, and moreover there is no evidence that hepatic impairment from other causes is associated with the development of adrenocortical hyperplasia. Alternatively it was suggested that adrenal metastases produce hyperfunction of the glands, since microscopic metastases are commonly seen. However, the very frequency of occurrence of such metastases in malignant disease, together with the comparative rarity of adreno-cortical hyperplasia. makes this unlikely. The idea that the malignant process constitutes a stress which results in a prolonged high output of cortisol was dismissed because of the frequency with which the syndrome is associated with tumours of particular organs. The possibility that an increased level of cortisol might exert a carcinogenic effect and render a latent malignancy manifest was also considered. In 1960 Allott and Skelton put forward the idea that the adrenal cortex becomes stimulated secondarily and in the same year Levine and Smith suggested that adrenocortical hyperplasia might result from elaboration by the tumour of corticotrophin or some substance having a similar physiological effect. In 1962 Meador, Liddle, Island, Nicholson, Lucas, Nuckton, and Leutscher investigated five patients with the syndrome and non-endocrine tumours, and assayed plasma and tumour extracts for A.C.T.H. using the method of Williams, Island, Oldfield, and Liddle (1961) which involves the injection of extracts into the femoral vein of hypophysectomized male rats and subsequent collection of blood from the left adrenal vein for cortisol determinations. Abnormal amounts of an A.C.T.H.-like substance were demonstrated in the plasma of these patients and in the extracts of both the primary tumours and secondary deposits. The A.C.T.H. content of the pituitary gland, in the two patients in whom such an assay was undertaken, was significantly less than the normal, as might be expected. All evidence of adrenal hyperfunction was abolished in two patients by adrenalectomy, confirming the view that the tumours were producing a corticotrophin-like substance rather than cortisol. The high glucocorticoid excretion is not depressed by dexamethazone, $2 \mathrm{mg}$. six hourly, nor is there any rise in the glucocorticoid excretion after the exhibition of metyrapone. The results of these tests are consistent with the autonomous production of a substance with A.C.T.H.-like activity by the tumour (Lipsett et al., 1964). Whether or not this A.C.T.H.-like substance is identical with normal corticotrophin remains unknown, but evidence suggests that it has certain similar physicochemical and biological characteristics (Liddle, Island, Ney, Nicholson, and Shimizu, 1963).

\section{HYPERCALCAEMIA}

Hypercalcaemia is a common and lethal complication of malignant disease and is commonly due to extensive osteolytic deposits which result in bone destruction and release of calcium into the extracellular fluid at rates in excess of that at which it can be cleared by the kidney. However, it is now well established that hypercalcaemia may occur in malignant disease in the absence of bone metastases.

In 1948 Albright and Reifenstein described a patient with renal carcinoma and a solitary pelvic metastasis in whom hypercalcaemia was transiently improved by irradiation of the deposit, and suggested the possibility of elaboration of a parathyroidlike hormone by the tumour. By 1956 Plimpton and Gellhorn were able to report 10 cases of hypercalcaemia without radiological evidence of bone metastases, confirmed by necropsy in seven. In three cases removal of the primary tumour was followed by a return to normocalcaemia with, in one case, a recurrence of progressive hypercalcaemia six months later when the tumour had palpably recurred.

Since then many case reports have accumulated. Occasionally hypercalcaemia may be the presenting symptom and the underlying malignancy may be overlooked. Lucas (1960) reported on a patient admitted to hospital with a three-week history of being 'unwell' and a two-week history of vomiting, polyuria, and polydipsia. Nothing abnormal was found on physical examination. The serum calcium level 
was $16.0 \mathrm{mg}$. per $100 \mathrm{ml}$, phosphate $2.2 \mathrm{mg}$. per $100 \mathrm{ml}$., and the alkaline phosphatase 20 KingArmstrong units per $100 \mathrm{ml}$. A skeletal survey was normal. A diagnosis of hyperparathyroidism was made, but no tumour was found when the neck was explored. The patient was comatose for 36 hours after operation, and his condition appeared terminal. However, the exhibition of cortisone led to a dramatic improvement, with a marked fall in the serum calcium level to $11.5 \mathrm{mg}$./100 ml. by the sixth postoperative day. After this the calcium level rose again and the patient died three days later. Necropsy showed abdominal carcinomatosis, possibly from a pancreatic primary. There was no evidence of bony metastasis. This history draws attention to the similarity of the biochemical findings to those of hyperparathyroidism, and to the beneficial influence of steroid therapy, both of which have been noted by other authors.

Again, there have been various theories put forward to explain the mechanism by which hypercalcaemia is produced in these patients. Increased absorption of calcium from the gut due to production of a vitamin D-like substance by the tumour has been suggested, but no confirmatory evidence has been forthcoming. Stone, Waterhouse, and Terry (1961) reported a patient with recurrent carcinoma of the cervix who developed severe hypercalcaemia unresponsive to steroids. Simultaneous exploration of the neck and pelvis revealed an inoperable pelvic mass and hyperplasia of the parathyroid glands, three of which were removed. Afterwards there was a dramatic fall in the serum calcium level which reached $8.4 \mathrm{mg}$. per $100 \mathrm{ml}$. on the day before she died. In this case the authors postulate the production of a parathyroid-stimulating substance by the tumour. Parathyroid hyperplasia has also been noted in a patient with lung cancer and hypercalcaemia reported by Massaro and Owen (1962).

The presence of some calcium-binding substance in the plasma has been suggested; Ericson, Clegg, and Hein (1955) demonstrated the presence of a phosphate-rich lipoprotein with marked calciumbinding properties in the egg-laying hen. Attempts to demonstrate the presence of a substance with similar properties in these patients have failed. Moreover, they develop the characteristic clinical syndrome of hypercalcaemia which is due to an increase in ionic calcium, and Walser (1962) showed that the increase in ionic calcium in these patients was proportional to the increase in total calcium, and found no evidence of increased chelation or complex formation. Watson (1963) also found that the complexed fraction was always normal.

The possibility that a parathyroid hormone-like substance was produced by these tumours was sug- gested by Albright and Reifenstein (1948). Ear attempts to demonstrate the activity of such substance in plasma and tumour extracts using bi assay techniques failed (Schatten, Ship, Pieper, and Bartter, 1958; Krane, 1961).

The availability of an antiserum to boving parathyroid hormone and the finding of immune chemical cross-reactivity between extracts of humas and bovine parathyroid extract (Tashjian, Levine, and Munson, 1964a) enabled these workers to examine tumour extracts from six patients with hypercalcaemia associated with neoplastic disease using a complement-fixation assay several hundree times more sensitive than the biological methods previously used (Tashjian, Levine, and Munsono 1964b). They were able to demonstrate an antigent present in suitable tumour extracts, closely reo sembling or identical with parathyroid hormone, if all six cases. Extracts of tumours not associated witht hypercalcaemia showed no serological activity. raised level of activity was found in the plasma of one patient, no dectactable activity being present in normal plasma. The parathyroid glands in one of these patients, when examined, were atrophio (Goldberg, Tashjian, Order, and Dammin, 1964).

Thus, there is abundant evidence that malignan neoplasms, mainly of the lung and kidney, may be associated with hypercalcaemia, even in the absence of bone metastases. There is also evidence of img munological detection of an antigen similar to para thyroid hormone in tumour extracts from some of these cases. However, no biological assay method has demonstrated the presence of such a substance despite the obvious biological effect in these patients. though this may be due to the rather unsatisfactor $\$$ bio-assay methods available. Again, the hypercas caemia of malignant disease not infrequent responds at least initially to the administration of cortisone, whereas the absence of such a response has been used as a diagnostic clue in patients with hyperparathyroidism (Dent, 1956). Finally there is the problem presented by the cases in which hyper plasia of the parathyroids has been noted.

It seems at least possible that the hypercalcaemia in these patients has more than one aetiology.

\section{WATER RETENTION}

In 1957 Schwartz, Bennett, Curelop, and Bartteळ reported studies on two patients with lung cancer who developed severe hyponatraemia, the plasma sodium level being initially below $120 \mathrm{mEq}$./litre, an $\vec{P}$ postulated sustained inappropriate secretion of anti⿱乛龰 diuretic hormone as the cause. The essential features of this syndrome were hyponatraemia and hypotonio city of the body fluids, together with the secretion of 
a urine hypertonic to plasma and containing considerable amounts of sodium despite the low plasma level. There was no clinical evidence of dehydration and the blood urea was not raised. Both the low plasma sodium and the renal sodium loss were improved by restriction of water intake. Both patients had normal renal function as measured by inulin clearance; and although both patients were shown to have adrenal metastases at necropsy, the urinary 17-hydroxycorticosteroid excretion and the response to A.C.T.H. were normal. The theory that the syndrome was due to sustained secretion of antidiuretic hormone was based on two facts. First, current views on renal physiology suggest that urine entering the distal tubule is hypotonic to plasma, and concentration of the urine depends on passive reabsorption of water under the influence of antidiuretic hormone. It follows that the secretion of a urine hypertonic to plasma in these patients, in the presence of a normal glomerular filtration rate, is most readily explained in terms of sustained secretion of anti-diuretic hormone. Secondly, a very similar syndrome can be produced in normal subjects given anti-diuretic hormone and unlimited fluid. The biochemical changes can be corrected in such normal subjects by restricting fluid intake even in the face of continued administration of anti-diuretic hormone. The secretion of anti-diuretic hormone in the patients with lung cancer was inappropriate in that it persisted despite the hypotonicity of the body fluids, which would normally result in decreased secretion of anti-diuretic hormone. The continuing sodium loss in the urine was attributed to expansion of the plasma volume due to retention of water with inhibition of aldosterone secretion. Schwartz et al. (1957) were unable to explain the mechanism of the sustained secretion of anti-diuretic hormone, Both patients had thoracic neoplasms which involved the vagi, and both had intracranial lesions. The authors therefore suggested that some reflex mechanism might have stimulated the continued secretion of anti-diuretic hormone from the pituitary gland. They drew attention to other reports of symptomless hyponatraemia in intracranial disease.

In the past two years evidence of secretion of an anti-diuretic hormone-like substance by these tumours has been growing. The first report of the detection of such a substance in tumour extracts came from Amatruda, Mulrow, Gallagher, and Sawyer (1963), and confirmation has come from the work of Bower and Mason (1964) and Lee, Jones, and Barraclough (1964). In each case the assay method has been biological, and therefore nonspecific. However, the last group of workers in particular laid down stringent criteria for attributing activity of tumour extracts to anti-diuretic hormone which were satisfied by their experimental studies.

Ross (1963) reported four cases of hyponatraemia associated with carcinoma of the bronchus, including two cases with evidence of proximal tubular damage with glycosuria and generalized aminoaciduria. In addition to features suggesting a dilutional hyponatraemia due to inappropriate secretion of antidiuretic hormone, these patients had failure of reabsorption of sodium due to the proximal tubular lesion. The urinary loss of sodium could not be stopped by the exhibition of $9 \alpha$-fluorohydrocortisone, and normal serum sodium levels could be achieved only if there was a simultaneous large sodium intake. The cause of the proximal tubular lesion remains uncertain.

\section{HYPERTHYROIDISM}

In 1956 de Gennes and Bricaire drew attention to the association of hyperthyroidism with malignant disease. Later they reviewed the cases reported up to 1962 (de Gennes, Bricaire, and Leprat, 1962). They quote cases of carcinoma of the gut, bronchus, prostate, uterus, and also reticulosis associated with hyperthyroidism. In 1963 Odell, Bates, Rivlin, Lipsett, and Hertz reported on thyroid function studies on 93 patients with chorion carcinoma seen over a period of five years. In seven patients they found laboratory evidence of increased thyroid activity. This included increased protein-bound iodine levels, increased $\mathrm{I}^{\mathbf{1 3 1}}$ uptake, and an increased basal metabolic rate. There was no clinical evidence for thyrotoxicosis other than tachycardia. In two patients, in whom treatment produced a remission of the primary malignant condition, the thyroid function tests returned to normal without specific anti-thyroid therapy.

They examined blood and tumour extracts from these patients for thyroid-stimulating hormone activity using the biological assay of Bates and Cornfield (1957). Raised levels were found in the serum of the two patients in whom the assay was undertaken and high activity was also found in tumour extracts from two cases. The possibility that chorionic gonadotrophin, which was grossly elevated in all patients, might have active thyroid-stimulating hormone activity was considered. However, there was no correlation between the level of excretion of chorionic gonadotrophin and the occurrence of hyperthyroidism; and also no thyroid-stimulating hormone activity was detected when 40,000 mouse units of chorionic gonadotrophin were given to chicks in the assay method used. The authors conclude that this is probably another example of hormone secretion by 
tumours. Confirmation of this view comes from Steigbigel, Oppenheim, Fishman, and Carbone (1964) who describe a case of embryonal carcinoma of the testis with raised plasma thyroid-stimulating hormone-like activity.

\section{CARCINOID SYNDROME}

The characteristic carcinoid syndrome usually occurs in patients with carcinoid tumours of the small gut of low grade malignancy and showing a typical histological picture with argentaffin-staining cytoplasmic granules. The tumours are frequently associated with overproduction of 5-hydroxytryptamine (5-HT) and an increased urinary excretion of 5-hydroxyindoleacetic acid (5-HIAA).

More recently, tumours arising from other sites than the small intestine, many of which have not been argentaffin, have been reported with similar clinical and biochemical findings. These tumours may arise from the stomach, pancreas, bronchus, or thyroid, all of which are foregut derivatives. The histology of such tumours often differs widely from the typical carcinoid pattern, with a tendency to be trabecular. The clinical carcinoid syndrome is frequent, and there is sometimes urinary excretion of 5-hydroxytryptophan (5-HTP), the precursor of 5-HT, as well as of 5-HIAA.

In some cases, the histology of pancreatic tumours associated with the carcinoid syndrome has resembled that of an adenocarcinoma of duct tissue, as in the case reported by Peart, Porter, Robertson, Sandler, and Baldock (1963). In others, it has resembled an islet cell tumour. Veer, Choufoer, Querido, Heul, Hollander, and Rijssel (1964) have reported a patient with a malignant islet-cell tumour with severe hypoglycaemia and the carcinoid syndrome. This patient remained normoglycaemic for about four years after excision of the primary pancreatic tumour, but hypoglycaemia recurred and the carcinoid syndrome appeared with excretion of excessive amounts of 5-HIAA in the urine when massive hepatic metastases had developed. Assay of tumour extracts for insulin and serotonin were negative. Bronchial tumours associated with the carcinoid syndrome have been reported as bronchial carcinoids, bronchial adenomata, and a few cases of oat-cell carcinoma (Williams and Azzopardi 1960; Gowenlock, Platt, Campbell, and Wormsley, 1964).

The present situation remains rather uncertain. Williams and Sandler (1963) have drawn attention to the differing features of carcinoid tumours derived from the three embryonic divisions of the gut. However, some bronchial and pancreatic neoplasms associated with abnormal indole excretion have had histological appearances typical of carcinoma. There is no report, as far as the authors know, of any case of carcinoid syndrome associated with tumours derived other than from primitive gut derivatives? and Moertel, Beahrs, Woolner, and Tyce (1965), 画 discussing a case of malignant carcinoid syndrom associated with a probable primary lesion of the thyroid gland, consider the possibility of a stem-cer origin common to these tumours.

\section{ERYTHROCYTOSIS}

The occurrence of erythrocytosis in association with renal tumours and renal cysts is well known, but $\frac{7}{8}$ has also been reported in association with cerebellar haemangiomata, virilizing tumours of the ovary and adrenals, uterine fibroma, hepatoma, and phaeochromocytoma. Unlike cases of polycythaemia verap patients with erythrocytosis associated with tumous usually show no leucocytosis or increased platelet count. The erythrocyte count often returns to norm after complete excision of the tumour.

The erythropoietic response to anoxia or anaemia in mammals is mediated by a mucoprotein hormone erythropoietin, the major source of which is the kidney. Waldmann (Lipsett et al., 1964) after a carefut study of 26 patients with erythrocytosis associate with tumours, demonstrated by bio-assay the presence of an erythropoiesis-stimulating factor ig renal cyst fluid, cyst fluid, and tumour extracts fror a cerebellar haemangioblastoma, and in the serum and tumour extract from a patient with phaeo chromocytoma. He showed too that this factor hat chemical and physical properties similar to those of the erythropoietin present in the serum of the anoxic subject, and was inactivated by treatment with af anti-serum prepared against purified human urinar erythropoietin. Assays of erythropoiesis-stimulating factor in tumour extracts and serum from patiento with polycythaemia associated with hepatic and pelvic tumours were negative. There is thus evidence for the production of erythropoietin or a closels related compound by at least some tumours associo ated with erythrocytosis. The available evidence is well reviewed by Penington (1965).

\section{ZOLLINGER-ELLISON SYNDROME}

This now well-known syndrome, described bo Zollinger and Ellison (1955), consists typically of aD non- $\beta$-cell, non-insulin-secreting islet-cell tumour of the pancreas with extreme gastric hyperacidity and intractable and atypical peptic ulceration. Late? Priest and Alexander (1957) drew attention to̊ chronic diarrhoea and an associated profound hypo $\mathbb{D}$ kalaemia which may be prominent clinical manifestae tions. This diarrhoea was initially attributed to the 
effect of the extreme acidity of the gastric juice on the $p \mathrm{H}$ of the intestinal contents, but this view is no longer entirely satisfactory since Espiner and Beaven (1962) reported a case of a woman with diarrhoea and hypokalaemia and a metastasizing islet-cell tumour who had complete achlorhydria. The tendency of ulcerogenic tumours of the pancreas to be associated with adenomata of one or more endocrine glands in about $26 \%$ of cases also remains unexplained. In particular parathyroid adenomata are found in about $8 \%$ of these patients.

The aetiology of the gastric hypersecretion is becoming better understood. Gregory, Tracy, French, and Sircus (1960) found that the non- $\beta$-cell adenomata in these patients contained up to thirtyfive times as much gastrin-like hormone as a similar weight of hog antrum. They also demonstrated a high hormone activity in a metastasis. Monaco, Lythgoe, and Waddell (1961), using an immunoassay, have closely identified this active principlewith gastrin. No gastric secretagogue activity has been demonstrated in endocrine adenomata other than the islet-cell tumours in these patients.

It seems likely, therefore, that the gastric hyperacidity may be the result of ectopic production of the potent gastric secretagogue gastrin by the pancreatic tumour. Whether or not other features of the syndrome have a hormonal basis is not known.

\section{PRECOCIOUS PUBERTY}

Five cases of precocious puberty in boys aged 1-8 years occurring in association with malignant hepatoblastomia have been reported. The fifth case was recorded by Hung, Blizzard, Migeon, Camacho, and Nyhan (1963) who also reviewed the previous cases. In these patients precocious puberty has been attributed to the production of chorionic gonadotrophin by the hepatic tumour with consequent intestitial-cell testicular hyperplasia, and in the case of Hung et al. (1963) the initial serum chorionic gonadotrophin level was 1,000 i.u./l., none being detectable in normal children. The urinary excretion of oxosteroids, testosterone, and oestrogens was also increased. In this patient, removal of the tumour and treatment with methotrexate and irradiation resulted in disappearance of chorionic gonadotrophin from the serum and regression of the signs of puberty. Evidence of secretory activity never reappeared despite rapid progression of the disease. The detection of a gonadotrophin resembling human gonadotrophin in a hepatoma extract has been described by Reeves, Tesluk, and Harrison (1959).

GYNAECOMASTIA The occurrence of gynaecomastia in patients with lung cancer has received scanty attention in the English and American literature. Three cases were reported by Hardy (1960), and the partial regression of the gynaecomastia following penumonectomy in one of these patients suggested that this association might be a further example of tumours producing hormone. Ginsburg and Brown (1961) showed an increased urinary excretion of oestrogen, and particularly of oestriol, in patients with carcinoma of the bronchus and osteoarthropathy, which fell to normal in six patients in four to eight weeks after operation. However, they found no relation between the level of oestrogen excretion and the presence of gynaecomastia. Moreover, in one patient studied in the first week after operation, the oestrogen excretion increased during the immediate postoperative period, suggesting that the increased oestrogen excretion was not directly related to the presence of the primary tumour. Thus the endocrine basis of the gynaecomastia associated with lung cancer remains uncertain.

\section{DISCUSSION}

The preceding sections have reviewed the growing reports of endocrine syndromes occurring in association with non-endocrine neoplasms, and presented the evidence that, in some cases, the tumours actually synthesize and secrete hormones or hormone-like substances. It is perhaps significant that, in all cases except the patients with carcinoid syndrome, the endocrine disturbance has been attributed to a peptide hormone. The current view of the biochemical basis of genetics postulates that protein synthesis is controlled by genetic information coded within the base sequence of the desoxyribonucleic acid (DNA) of the cell nucleus, this information being passed from parent to offspring at the time of zygote formation and subsequently from each generation of cells to the next during cell division. It follows that all cells must therefore contain an identical complement of DNA, so that all contain the coded information necessary for the synthesis of all normal proteins. The limitation of this diffuse synthetic potential is the result of the process we call cell differentiation. It is conceivable therefore that, as the malignant cell reverts to a more primitive type, release from normal suppressor mechanisms occurs and this may result in the ectopic synthesis of peptide hormones. Such synthetic activity might on occasion result in the production of peptides identical with normal hormones, and in other instances mutation occurring within the malignant cell might result in the formation of peptides with hormonal activity but with sufficient structural abnormality to render them immunologically distinct from the normal hormone. 
The secretion of indoles by tumours, with the development of the carcinoid syndrome, is less readily explicable; for the present it seems wise to regard this phenomenon, which is limited to tumours occurring in tissues derived from the primitive gut, as the result of tumour formation from argentaffin cell rests in the tissues of origin.

An alternative suggestion made by Unger et al. (1964) is that certain malignant tumours may have an increased avidity for hormones and act as 'hormone sponges'. In support of this theory they quote the work of Ghose, Nairn, and Fothergill (1962), who studied the uptake of rabbit serum proteins conjugated with lissamine rhodamine by benzpyrene-induced fibrosarcoma in rats and the Ehrlich ascites tumour in Swiss albino mice. They showed that plasma proteins could be taken up by the malignant cells without prior extracellular hydrolysis, a process which does not occur in most normal tissues. Unger et al. (1964) postulate that these hormones are taken up by the tumour and accumulate within it. Accelerated breakdown of malignant cells in a rapidly enlarging tumour might then result in the unregulated release of large amounts of hormone. This theory would suggest that multiple hormones might be stored by the tumour and subsequently released. In fact, comparatively few cases have so far been recorded. The metastasis of a bronchogenic cancer examined by Unger et al. (1964) contained both insulin and glucagon, and Schonfeld et al. (1961) reported the simultaneous occurrence of polycythaemia and hypoglycaemia in a patient with hepatoma. Rees, Rosalki, and Maclean (1960) and Daly, Nelson, and Rose (1963) reported cases of adrenocortical overactivity and hyponatraemia and Rees's case also had terminal hypercalcaemia. Law, Liddle, Scott, and Tauber (1965) reported the production of A.C.T.H., melanoyte-stimulating hormone and gastrin by an islet cell tumour of the pancreas. It must be remembered that an excess of one particular hormone normally dominates the picture and careful investigation to detect possible multiple hormone-like substances in tumour extracts or body fluids in these patients has seldom been undertaken. Moreover, if impaired degradation of hormones is an important factor in the aetiology of these syndromes, it may well be that impaired synthesis in the production of an enzyme or enzymes necessary for the degradation of one particular hormone might occur in the malignant cell and so lead to the accumulation and irregular release of that hormone.

Another interesting facet of these syndromes is the liability of tumours arising in particular situations or of a particular histological type to be associated with a particular endocrine effect. For example, bronchial carcinoma is the tumour most commonly reported in association with endocrine dysfunction, and whils oat-cell carcinomas are the histological type usually. associated with both Cushing's syndrome and hypos natraemia, hypercalcaemia is more common witt squamous cell growths. Attention has already bee drawn to the association of adrenal cortical hyper ${ }^{\bar{s}}$. plasia with thymoma, and to the rather unusa $\$$ histological picture of the thymic tumours in these cases.

The current impression is still that these syndrome $\vec{P}$ are exceptional. However, the detection of large amounts of both insulin and glucagon in a metastasig from a patient dying of malignant disease withoug any overt evidence of endocrinopathy, the patienit being one of three selected at random (Unger et al $l_{i v}^{+}$ 1964), should lead us to consider how many cases are being missed. It is well known that patients witho bronchial cancer often show increased levels of plasma cortisol, an exaggerated response to A.C.T.H., and impaired glucose tolerance (Werk and Sholiton 1960; Hymes and Doe, 1962), even in the absence of clinical evidence of adrenal cortical hyperplasia? Hypercalcaemia is a common complication but may remain undetected in terminal malignant disease? especially in patients without evidence of skeletait metastases. As always, awareness of the existence of these syndromes leads to an increase in the number of cases detected.

The possibility that these tumours may synthesiz hormone-like substances as a result of escape from the normal processes regulating protein synthesis is a challenging concept which may have significant implications for an understanding of the functionat pathology of malignancy. The possibility that ectopic production of other proteins of biological significances may occur is an unexplored field.

\section{REFERENCES}

Albright, F., and Reifenstein, E. C. (1948). The Parathyroid Gland and Metabolic Bone Disease. Williams and Williams, Baltimore

Allott, E. N., and Skelton, M. O. (1960). Lancet, 2, 278.

Amatruda, T. T., Jr., Mulrow, P. J., Gallagher, J. C., and Sawyecr W. H. (1963). New Engl. J. Med., 269, 544.

August, J. T., and Hiatt, H. H. (1958). Ibid., 258, 17.

Bates, R. W., and Cornfield, J. (1957). Endocrinology, 60, 225

Bower, B. F., and Mason, D. M. (1964). Clin. Res., 12, 121.

Brown, W. H. (1928). Lancet, 2, 1022 .
Butterfield, W. J. H., Kinder, C. H., and Mahler, R. F. (1960) Ibid., 1, 703.

Daly, J. J., Nelson, M. A., and Rose, D. P. (1963). Postgrad. med. J(্) $39,158$.

Dent, C. E. (1956). Brit. med. J., 1, 230.

Doege, K. W. (1930). Ann. Surg., 92, 955.

Ericson, A. T., Clegg, R. E., and Hein, R. E. (1955). Science, 122, 199:
Espiner, E. A., and Beaven, D. W. (1962). Quart. J. Med., 31, 447. (D)

Gennes, L. de, and Bricaire, H. (1956). Presse méd., 64, 2039.

,-- , and Leprat, J. (1962). Ibid., 70, 2137.

Ghose, T., Nairn, R. C., and Fothergill, J. E. (1962). Nature (Lond. 196, 1108.

Ginsburg, J., and Brown, J. B. (1961). Lancet, 2, 1274. 
Goldberg, M. F., Tashjian, A. H., Jr., Order, S. E., and Dammin, G. J. (1964), Amer. J. Med., 36, 805.

Gowenlock, A. H., Platt, D. S., Campbell, A. C. P., and Wormsley, K. G. (1964). Lancet, 1, 304.

Greenberg, E., Divertie, M. B., and Woolner, L. B. (1964). Amer. J. med., 36, 106.

Gregory, R. A., Tracy, H. J., French, J. M., and Sircus, W. (1960). Lancet, 1, 1045.

Hardy, J. D. (1960). J. Amer. med. Ass., 173, 1462.

Hung, W., Blizzard, R. M., Migeon, C. J., Camacho, A. M., and Nyhan, W. L. (1963). J. Pediat., 63, 895.

Hymes, A. C., and Doe, R. P. (1962). Amer. J. Med., 33, 398.

Krane, S. M. (1961). Case Records of the Massachussets General Hospital. New Engl. J. Med., 265, 953.

Law, D. H., Liddle, G. W., Scott, H. W., and Tauber, S. D. (1965). Ibid., 273, 292.

Lee, J., Jones, J. J., and Barraclough, M. A. (1964). Lancet, 2, 792.

Levine, R., and Smith, M. (1960). Clin. Endocr., 1, 344.

Liddle, G. W., Island, D. P., Ney, R. L., Nicholson, W. E., and Shimizu, N. (1963). Arch. intern. Med., 111, 471.

Lipsett, M. B., Odell, W. D., Rosenberg, L. E., and Waldmann, T. A. (1964). Ann. int. Med., 61, 733.

Lowbeer, L. (1961). Amer. J. clin. Path., 35, 233.

Lucas, P. F. (1960). Brit. med. J., 1, 1330.

Massaro, D. J., and Owen, J. A., Jr. (1962). Amer. Rev. resp. Dis., $85,727$.

Meador, C. K., Liddle, G. W., Island, D. P., Nicholson, W. E., Lucas, C. P., Nuckton, J. G., and Leutscher, J. A. (1962). J. clin. Endocr., 22, 693.

Miller, D. R., Bolinger, R. E., Janigan, D., Crockett, J. E., and Friesen, S. R. (1959). Ann. Surg., 150, 684.

Moertel, C. G., Beahrs, O. H., Woolner, L. B., and Tyce, G. M. (1965). New Engl. J. Med., 273, 244.

Monaco, A. P., Lythgoe, J. P., and Waddell, W. R. (1961). Lancet, 2, 1016 .

Nadler, W. H., and Wolfer, J. A. (1929). Arch. intern. Med., 44, 700.

Odell, W. D., Bates, R. W., Rivlin, R. S., Lipsett, M. B., and Hertz, R. (1963). J. clin. Endocr., 23, 658.

Oleesky, S., Bailey, I., Samols, E., and Bilkus, D. (1962). Lancet, 2, 378.

Peart, W. S., Porter, K. A., Robertson, J. I. S., Sandler, M., and Baldock, E. (1963), Ibid., 1, 239.

Penington, D. G. (1965). Proc. roy. Soc. Med., 58, 488.

Plimpton, C. H., and Gellhorn, A. (1956). Amer. J. Med., 21, 750.

Priest, W. M., and Alexander, M. K. (1957). Lancet, 2, 1145.
Prunty, F. T. G., Brooks, R. V., Dupré, J., Gimlette, T. M. D. Hutchinson, J. S. M., McSwiney, R. R., and Mills, I. H. (1963) J. clin. Endocr., 23, 737.

Rees, J. R., Rosalki, S. B., and Maclean, A. D. W. (1960). Lancet, $2,1005$.

Reeves, R. L., Tesluk, H., and Harrison, C. E. (1959). J. clin. Endocr., 19,1651 .

Riggs, B. L., Jr., and Sprague, R. G. (1961). Arch. intern. Med., 108, 841.

Ross, E. J. (1963). Quart. J. Med., 32, 297.

(1965). Proc. roy. Soc. Med., 58, 485.

Samaan, N., Lal, F., Fraser, R., and Welbourn, R. B. (1965). Brit. med. J., 2, 195.

Schatten, W. E., Ship, A. G., Pieper, W. J., and Bartter, F. C. (1958). Ann. Surg., 148, 890.

Schonfeld, A., Babbott, D., and Gundersen, K. (1961). New Engl. J. Med., 265, 231.

Schwartz, W. B., Bennett, W., Curelop, S., and Bartter, F. C. (1957). Amer. J. Med., 23, 529.

Soutter, L., Sommers, S., Relman, A. S., and Emerson, C. P. (1957). Ann. Surg., 146, 424.

Steigbigel, N. H., Oppenheim, J. J., Fishman, L. M., and Carbone, P. P. (1964). New Engl. J. Med., 271, 345.

Stern, J. B. (1960). Lancet, 1, 546.

Stone, G. E., Waterhouse, C., and Terry, R. (1961). Ann. intern. Med., 54, 977.

Tashjian, A. H., Jr., Levine, L., and Munson, P. L. (1964a). Endocrinology, 74, 244.

, - - and - (1964b). J. exp. Med., 119, 467.

Tranquada, R. E., Bender, A. B., and Beigelman, P. M. (1962). New Engl. J. Med., 266, 1302.

Unger, R. H., Lochner, J. de V., and Eisentraut, A. M. (1964). J. clin. Endocr., 24, 823.

Veer, J. van der S., Choufoer, J. C., Querido, A., Heul, R. O. van der, Hollander, C. F., and Rijssel, T. G. van. (1964). Lancet, 1, 1416.

Walser, M. (1962). J. clin. Invest., 41, 1454.

Watson, L. (1963). Postgrad. med. J., 39, 646.

Werk, E. E., Jr., and Sholiton, L. J. (1960). Cancer (Philad.), 13, 469.

Whitney, J. E., and Massey, C. G. (1961). J. clin. Endocr., 21, 541.

Williams, E. D., and Azzopardi, J. G. (1960). Thorax, 15, 30.

- and Sandler, M. (1963). Lancet, 1, 238.

Williams, W. C., Jr., Island, D., Oldfield, R. A. A., Jr., and Liddle, G. W. (1961). J. Clin. Endocr., 21, 426.

Zollinger, R. M., and Ellison, E. H. (1965). Ann. Surg., 142, 709. 